\title{
Clinicomycological Profile of Superficial Fungal Infections Caused by Dermatophytes in a Tertiary Care Centre of North India
}

\author{
Nidhi Negi*, Vibha Tripathi, Reshmi Chanda Choudhury, Jitendra Singh Bist, \\ Neeti Kumari and Iva Chandola
}

\author{
Department of Microbiology, SGRRIM \& HS Patel Nagar, Dehradun, India \\ *Corresponding author
}

\section{A B S T R A C T}

Uttrakhand has a humid climate for most of the year and also receives heavy rainfall during monsoons. Thus the environmental conditions are conducive for the development of superficial mycoses. The present study was carried out to know the prevalence of superficial fungal infection caused by dermatophytes and to speciate them which may help

Keywords

Superficial fungal

infections,

Dermatophytes,

Tertiary care.

Article Info

Accepted:

26 June 2017

Available Online:

10 August 2017 to control the infection. The aim of this study was to determine the prevalence of superficial fungal skin infections caused by dermatophytes, to study the clinic-mycological pattern and to speciate the isolated ones using standard mycological tests. This was a prospective study carried out over a period of one year from June 2014 to May 2015. Samples were obtained from patients who attended the dermatology department of SGRRIM\&HS, Patel nagar Dehradun. Sample included skin scraping (91.34\%) followed by nail scraping or clipping $(6.7 \%)$ and plucked hair $(1.9 \%)$. these were subjected to direct microscopy and culture. Out of total 104 clinically diagnosed cases of superficial fungal infection, 57 (54\%) samples were positive by direct microscopy and culture. 87 (83\%) were culture positive out of which $40(45.9 \%)$ grew dermatophytes and 47 (54\%) grew non dermatophytes. In our study non dermatophytes grew more in number as compared to dermatophytes but the difference was not statistically significant $\mathrm{P}$ value 0.87 . Dermatophytes are assuming greater significance both in developed and developing countries particularly due to the advent of immunosuppressive drugs and diseases like AIDS. Knowing their clinicomycological pattern may help somewhere in prevention as well as diagnosing this infection.

\section{Introduction}

Superficial fungal infection is the term given to infections caused by a group of fungi limited to upper layer of skin, hair and nail. Inspite of the fact that they are less dangerous or harmful for the survival of an individual, they are of importance to us because of the morbidity they cause, carry risk of person to person transmission and hence their worldwide distribution. Also a refractory superficial fungal infection may indicate an underlying immunocompromised state [1].
Along with the dramatic rise in invasive fungal infections a parallel increase in superficial mycoses has also been noted in the past decade \& they have now become one of the world's most common skin diseases affecting millions of people worldwide [2].

Dermatophytes are the prevalent causes of cutaneous fungal infections. Terms "Ring worm", "tinea" or "dermatophytosis", are common terms used for infections caused by 
them. Dermatophytosis is defined as the infection of the skin, hair and the nails caused by a group of closely related keratinophilic fungi called dermatophytes, all of which produce enzyme keratinase [3, 4]. Some of the factors promote dermatophytic infections like close contact with animals, use of certain drugs like antibiotics and steroids and trend of living in community [5].

The classical presentation of tinea infection is a lesion with central clearing which is surrounded by an advancing red, scaly, elevated border. This inflammation assists in colonization and may result in vesicles on the border of the affected area. The inflammation tends to be more in atopic persons and those infected with zoophilic fungi [6].

Reaction to a dermatophyte infection may range from mild to severe as a consequence of the host's reactions to the metabolic products of the fungus, the virulence of the infecting strain or species, the anatomic location of the infection, and local environmental factors [7].

The prevalence of these infections also tend to increase with age, change in geographic location and climate.

These infections are especially common in tropical countries like India due to environmental factors like heat and humidity. In addition, the risk factors include socioeconomic conditions like overcrowding, poverty and neglect of personal hygiene [8]. Although mortality due to dermatophytosis has not been reported till date it does cause morbidity and hence the cosmetic importance of these infections cannot be ignored [9].

\section{Materials and Methods}

\section{Study population and period}

This study was conducted in department of microbiology, on samples from 104 subjects for a period of one year from June 2014 to May 2015, presenting in skin opd of a tertiary care center of North India with clinical features suggesting of fungal skin infections after obtaining written informed consent.

\section{Selection of Subjects}

\section{Inclusion criteria}

All individuals presenting in skin opd with a clinical diagnosis of superficial fungal infection were included in the study.

\section{Exclusion criteria}

Individuals already taking antifungal treatment were not included in the study.

\section{Sample collection and processing}

The samples were collected from skin, hairs and nail from the patients, depending on the clinical condition of the patient and the suspected site of infection. The affected area was cleaned with $70 \%$ ethyl alcohol and allowed to dry. Skin scales, crusts and pieces of nail or hairs were collected in clean white paper packets. Skin lesions were sampled from the erythematous, peripheral, actively growing margins of the lesions. In case of hair samples the dull lusterless hair and stubs of hair were chosen and plucked by sterile epilator forceps, nail samples were taken from the deeper part of the discoloured or dystrophic parts of nails [3].

\section{Direct microscopy}

A portion of the sample was taken on a grease-free slide for microscopy. The specimen was then subjected to potassiumhydroxide $(\mathrm{KOH})$ wet preparation of various concentrations (10\%, 20\% and 40\%) depending upon the type of clinical specimen for the presence of fungal elements. The prepared slide was later examined under low 
(10 X) and high (40 X) Magnification of a simple light microscope for the presence of yeast cells, hyphae and arthroconidia. The fungal elements appear as highly refractile, hyaline septate branching filaments. [3]

\section{Culture}

Culture was performed on Sabouraud dextrose agar (SDA) with and without chloramphenicol $50 \mathrm{mg} / \mathrm{L}$. Pure isolates were generated by sub-culturing on Sabouraud Dextrose And Potato Dextrose Agar (PDA) media respectively for both visual and microscopic examinations of cultural (colour and growth pattern) and Morphological characteristics respectively for further differentiation. After morphological examination by microscopy, it was put on dermatophyte test media (DTM) for further confirmation. [3]

\section{Results and Discussion}

Out of total 104 clinically diagnosed cases of superficial fungal infection, 57 (54\%) samples were positive by direct microscopy and culture. $87(83 \%)$ were culture positive out of which $40(45.9 \%)$ grew dermatophytes [Table $1]$.

The 104 clinically diagnosed cases of superficial fungal infections were distributed between the ranges of 1-80 years. The most common age group to be affected was $31-40$ years $(28 \%)$ followed by 21-30 years $(25 \%)$. Least common age group affected was 41-50 years (19\%). [Table 2]. Males were more commonly affected $62(60 \%)$ than females 42 (40\%), majority of the sample included skin scraping $(91.34 \%)$ followed by nail scrapping or clipping $(6.7 \%)$ and least commonly, plucked hair (1.9\%). In the present study most commonly affected group was of students (26\%) followed by housewife (22\%) and agriculture workers (18\%). Majority were from low socio economic group followed by middle socio economic group and least from high socio economic group [Table 4].

Out of a total of 104 clinically diagnosed cases of superficial fungal infections, 57 cases (54\%) showed positivity in both $\mathrm{KOH}$ mount and culture. 12 cases $(11 \%)$ were positive in $\mathrm{KOH}$ mount only. 27 cases $(25 \%)$ showed positivity only in culture. 8 suspected cases of superficial fungal infections $(7.6 \%)$ were negative both by $\mathrm{KOH}$ mount and culture [Table 3]. Trichophyton mentegrophytes was the most common isolate $(24.13 \%)$ followed by Trichophyton rubrum (10.3\%), Microsporum gypseum, Microsporum canis (3.4\%). Least common isolates was Epidermophyton floccosum (2.3\%).

In the present study, the commonest age group involved was 31-40 (28\%) years and 21-30 (25\%) years with males out numbering females. This age predilection has been suggested due to the involvement of this age group in outdoor activity. In addition, males do more exhaustive physical work and prolonged exposure in sun causes excessive sweating. Also the tight fittings and synthetic clothing particularly in males provide damp, sweaty and warm skin conditions. Comparable observations have been done by other authors also. [11, 12]

The lower incidence in females could be due to not paying attention to the lesion they have, as in most of the communities females do not bother about their health and they do not get enough time for reporting in hospitals due to the prevailing social stigma in rural population and poor health seeking behavior of females $(12,13)$. The incidence of infection are closely related to the site of infection and consequently to the clinical materials collected. In the present study skin scales represent $91 \%$ of cases, while nails account for $7 \%$ and hair 2\%. Similar findings have been shown in studies from abroad also [2]. 
In the present study most of the cases were of students 28(26.9\%) followed by housewife $23(22.1 \%)$ and agriculture workers $19(18.3 \%)$. In case of student's higher freedom of movement, carelessness, common sharing of articles by fellow students and perhaps lack of guidance regarding personal hygiene could be the factors in exposing students to increased dermatophytic infections [14]. In agricultural workers this may be due to increased physical activity and increased opportunity for exposure to plants, animals and soil (15). A study carried out from West Bengal found that Dermatophytoses are related to activity, living conditions and age groups [16].

Higher prevalence of dermatophytic infection was seen in low income group, 62/ 104, $(59.61 \%)$ followed by middle income group $34 / 104(32.6 \%)$ and least common in high income group $7 /(6.73 \%)$, which is similar to the observation of Kamothi et al., from Rajkot in (2010), who reported that higher prevalence of dermatophytic infection was seen in low income group than middle income group (17). The reason behind this may be the poor living conditions, large family size and close contact, either directly or by sharing facilities, including combs and towels between family members in low socio economic people.

\section{Comparison of $\mathrm{KOH}$ mounts findings with culture findings}

Out of a total of 104 clinically diagnosed cases of superficial fungal infections, 57 cases (54\%) showed positivity in both $\mathrm{KOH}$ mount and culture. 12 cases $(11 \%)$ were positive in $\mathrm{KOH}$ mount only. 27 cases $(25 \%)$ showed positivity only in culture. 8 suspected cases of superficial fungal infections $\mathbf{( 7 . 6 \% )}$ were negative both by $\mathrm{KOH}$ mount and culture. These variations between microscopy and culture have also been noted by Grover S, Roy P. from North-East India (18). In various studies, Bindu V from Calicut, Vikesh kumar Bhatia in (2014) from Himachal Pradesh and Kamothi from Rajkot who reported that $\mathrm{KOH}$ positivity rate was higher than culture positivity $(11,12,17)$.

Table.1 Comparison of $\mathrm{KOH}$ mount with culture findings $(\mathrm{n}=104)$

\begin{tabular}{|l|c|c|c|}
\hline \multirow{2}{*}{ KOH mount } & \multicolumn{2}{|c|}{ Culture } & \multirow{2}{*}{ Total (\%) } \\
\cline { 2 - 3 } & Positive & Negative & \\
\hline Positive & 57 & 12 & 69 \\
\hline Negative & 27 & 8 & 35 \\
\hline Total & 84 & 20 & 104 \\
\hline
\end{tabular}

Table.2 Demographic distribution of subjects

\begin{tabular}{|l|l|}
\hline Range in years & No. of cases \% \\
\hline 1 to 10 & $4(3.8 \%)$ \\
\hline 11 to 20 & $15(4.8 \%)$ \\
\hline 21 to 30 & $26(25 \%)$ \\
\hline 31 to 40 & $30(28 \%)$ \\
\hline 41 to 50 & $20(19 \%)$ \\
\hline 51 to 60 & $5(4.8 \%)$ \\
\hline 61 to 70 & $3(2.8 \%)$ \\
\hline 71 to 80 & $1(0.9 \%)$ \\
\hline
\end{tabular}


Table.3 Sex wise distribution of clinical types of superficial fungal infection

\begin{tabular}{|l|l|l|l|}
\hline Type & Male & Female & Total \\
\hline T.corporis & $19(65.5 \%)$ & $10(34.48 \%)$ & $29(27.8 \%)$ \\
\hline T.cruris & $13(54.16 \%)$ & $11(45.83 \%)$ & $24(23.0 \%)$ \\
\hline T.unguium & $5(38.46 \%)$ & $8(61.53 \%)$ & $13(12.5 \%)$ \\
\hline T.capitis & $0(0.00 \%)$ & $2(100 \%)$ & $02(1.9 \%)$ \\
\hline T.pedis & $11(84.61 \%)$ & $2(15.38 \%)$ & $13(12.5 \%)$ \\
\hline T.faciei & $8(80.0 \%)$ & $2(20.00 \%)$ & $10(9.6 \%)$ \\
\hline T.manuum & $6(42.85 \%)$ & $8(57.14 \%)$ & $14(13.5 \%)$ \\
\hline T.corporis with T.cruris & $11(73.33 \%)$ & $4(26.66 \%)$ & $15(14.5 \%)$ \\
\hline P. versicolar & $0(0.00 \%)$ & $3(100 \%)$ & $03(2.8 \%)$ \\
\hline
\end{tabular}

Table.4 Sample distribution according to socio economic conditions of the patients $(n=104)$

\begin{tabular}{|l|l|l|}
\hline Socio economic status & No. of cases & Percentage (\%) \\
\hline Low income group & 62 & $59.61 \%$ \\
\hline Middle income group & 34 & $32.6 \%$ \\
\hline High income group & 07 & $6.73 \%$ \\
\hline
\end{tabular}

Table.5 Distribution of isolated Dermatophytic species among the clinical pattern of fungal infections

\begin{tabular}{|c|c|c|c|c|c|c|c|c|c|}
\hline \multicolumn{10}{|c|}{ Dermatophytic species } \\
\hline Species & $\begin{array}{l}\text { T.capitis } \\
\text { (\%) }\end{array}$ & $\begin{array}{l}\text { T.ungium } \\
(\%)\end{array}$ & $\begin{array}{l}\text { T.faciei } \\
(\%)\end{array}$ & $\begin{array}{l}\text { T.manuum } \\
(\%)\end{array}$ & $\begin{array}{l}\text { T.pedis } \\
(\%)\end{array}$ & $\begin{array}{l}\text { T.corporis } \\
(\%)\end{array}$ & $\begin{array}{l}\text { T.cruris } \\
(\%)\end{array}$ & $\begin{array}{l}\text { T.corporis } \\
\text { with } \\
\text { T.cruris }(\%\end{array}$ & $\begin{array}{l}\text { P. } \\
\text { versicolor } \\
(\%)\end{array}$ \\
\hline $\begin{array}{l}\text { T.mentegrophyt } \\
\text { es }\end{array}$ & $0(0.0 \%)$ & $2(25.0 \%)$ & $2(40.0 \%)$ & $3(42.8 \%)$ & $3(25.0 \%)$ & $4(26.6 \%)$ & $5(22.7 \%)$ & $2(11.7 \%)$ & $0(0.0 \%)$ \\
\hline T. rubrum & $1(50.0 \%)$ & $2(25.0 \%)$ & $0(0.0 \%)$ & $0(0.0 \%)$ & $0(0.0 \%)$ & $1(6.6 \%)$ & $3(13.6 \%)$ & $2(11.7 \%)$ & $2(100 \%)$ \\
\hline M. cannis & $0(0.0 \%)$ & $0(0.0 \%)$ & $0(0.0 \%)$ & $0(0.0 \%)$ & $0(0.0 \%)$ & $1(6.6 \%)$ & $1(4.5 \%)$ & $1(5.8 \%)$ & $0(0.0 \%)$ \\
\hline M. gypsium & $0(0.0 \%)$ & $0(0.0 \%)$ & $0(0.0 \%)$ & $0(0.0 \%)$ & $1(8.3 \%)$ & $0(0.0 \%)$ & $1(4.5 \%)$ & $1(5.8 \%)$ & $0(0.0 \%)$ \\
\hline $\begin{array}{l}\text { Epidermophyto } \\
n\end{array}$ & $0(0.0 \%)$ & $1(12.5 \%)$ & $0(0.0 \%)$ & $0(0.0 \%)$ & $1(8.3 \%)$ & $0(0.0 \%)$ & $0(0.0 \%)$ & $0(0.0 \%)$ & $0(0.0 \%)$ \\
\hline Total & $1(50 \%)$ & $5(62.5 \%)$ & $2(40 \%)$ & $3(42.8 \%)$ & $5(41.6 \%)$ & $6(39.8 \%)$ & $10(90.6 \%)$ & $6(35.0 \%)$ & $2(100 \%)$ \\
\hline
\end{tabular}

Among dermatophytes, Trichophyton mentagrophyte was the predominant dermatophyte $(24 \%)$ followed by Trichophyton rubrum (10\%), Microsporum cannis $(3.4 \%)$ and Microsporum gypseum (3.4\%), least common isolate was of Epidermophyton floccosum (2.3\%). The difference in isolation rates of dermatophytes verses non-dermatophytes was found statistically non-significant $\mathrm{p}$ value $=0.87$.
Similar results were also reported by other workers previously from Himachal Pradesh in 2014 (19). But the findings differ in other studies from India as well as outside India, according to which Trichophyton rubrum was the predominant fungal pathogen than Trichophyton mentagrophyte $(2,17,20)$. This variation is possibly due to the different geographical regions and warm climatic conditions in southern and western part of country. 
Some studies have also reported about the prevalence of Trichophyton rubrum in chronic dermatophytosis (21), as it is a slow growing organism, so there is a possibility that other dermatophyte species might overgrow or mask the growth of Trichophyton rubrum while attempting isolation. (19).

T. mentegrophytes, the predominant species was found associated mainly with Tinea corporis (26.6\%) and Tinea cruris (22.7\%) however it was seen in all other Tinea condition except Tinea capitis. Similar observation have been made by authors from Himachal Pradesh in 2014, (11).

The majority of $T$. rubrum were isolated in Tinea cruris $(13.6 \%)$ followed by Tinea ungium (25\%) and Tinea corporis with Tinea cruris (11.7\%). similar finding have been shown in other studies also (22).

M. cannis and M. gypseum were isolated same in Tinea corporis (6.6\%) followed by Tinea cruris $(4.5 \%)$ Tinea corporis with cruris (5.8\%), which is similar to findings from abroad studies (2).

Epidermophyton spp. were isolated in Tinea ungium (12.5\%) and Tinea pedis (8.3\%). Similar results were also reported by other workers previously from Bijapur (2004) (23).

The current study shows Tinea.corporis to be the commonest clinical type of superficial mycoses followed by Tinea cruris, \& Tinea corporis with Tinea cruris, Tinea mannum, Tinea unguim and Tinea pedis.

Tinea corporis was the most common clinical condition observed in which various exposed part of the body are affected followed by Tinea cruris in groin and surrounding areas are affected. Similar observation has been made by Asticciol S 2008, Bhatia \& Sharma
2014, Kamothi MN 2010. This tinea condition is more common in males due to tight clothing, maceration and high rate of sweating in groin and waist region make this site more vulnerable to dermatophytosis. (24)

However certain studies conducted in North East India, West Orissa, Rajkot, indicating that many factors like selection of study groups, life style, levels of personal hygiene, climatic conditions affect the patterns and types of superficial fungal skin infections. (9) Most of the incidence of Tinea. mannum and Tinea. unguium in females has been found in our study, which may be attributed to repeated prolonged exposures to water and different types of detergents (especially in kitchen) while performing daily domestic chores. Similar findings have been shown by Bhatia and Sharma in 2014.

In our study most of the cases of Tinea pedis were seen in male than female cases. And our study group mainly comprised of students (26\%) because of wearing of closed footwear socks and shoes for a long period in all weather. These promotes sweating and sweat retention a-milieu conducive to fungal growth. These also providing damp conditions especially in inter-digital spaces $(11,14)$

After performing this study it was observed that non-dermatophyte group was involved more than dermatophyte group in causing superficial fungal infection. However considering the duration of study, we suggest that extensive research can be carried out further in a more elaborative way.

\section{References}

Brendan P. Kelly. Superficial fungal infections in Chicago.Pediatrics in Review : 2012 :33;4-22 
Asticciol S, Di Silverio A, Sacco L, Fusi I, Vincent L, Romero E. Dermatophyte infections in patients attending a tertiary care hospital in northern Italy. New Microbiologica. 2008; 31: 543-8.

Chandra J. Dermatophytes. In: Chander J, editor. Textbook of medical mycology. $3^{\text {rd }}$ ed. Mehta Publishers: 2009; p. 12242.

Ananthanarayan R, Jayaram Paniker CK. Medical mycology. In: Paniker AN, editor. Textbook of microbiology. $8^{\text {th }}$ ed. Hyderabad: Universities Press: 2009; p. 600-17.

Falahati M, Akhlagi L, Lari AR, Alaghebandan R. Epidemiology of dermatophytoses in an area south of Tehran, Iran. Mycopathologia. 2003; 156: 279-87.

Hainer BL. Dermatophyte infection. American Family Physician. 2003; 67: 101-9.

Esquenazi D, Alviano CS, Desouza W, Rozental S. The influence of surface carbohydrates during in vitro infection of mammalian cells by the dermatophyte Trichophyton rubrum. Res. Microbiol. 2004; 155: 144-153.

Sharma S, Berthakur AK. A clinic epidemiological study of dermatophytosis in north east India. Indian $\mathbf{J}$ of Dermatology Venerology and Leprology. 2007; 73: 427-8.

Venkatesan G, Ajar S, Munniganeshan AG, Janaki C, Shankar SG. Trichophyton rubrum- the predominant aetiological agent in human dermatophytosis in Chennai, India. Afr J Microbiol Res. 2007; 2: 9-12.

Vikesh kumar Bhatia, Prakash chand Sharma.Epidemiological studies on Dermatophytosis in human patients in Himachal Pradesh, India SpringerPlus 2014 3;134.

Bindu V, Pavithran K. Clinico - mycological study of dermatophytosis in Calicut.
Indian J Dermatol Venereol Leprol. 2002; 68: 259-61.

Georg, L.K. Epidemiology of the dermtophytoses: sources of infection, modes of transmission and epidemicity. Ann. N. Y. Acad. 1960; Sci. 89: 69- 77.

Chmel L.Zoophilic dermatophytes and infections in man. Med. Mycol. 1980; 8: 61-66.

Kligman A M. Tinea capitis due to M.audouinii and M.canis.Arch. Dermatol. 1955; 71: 313-48.

De Aguiar Peres NT, Albuquerque Maranhao FC, Rossi A, Martinez-Rossi NM. Dermatophytes: host-pathogen interaction and antifungal resistance. An Bras Dermatol. 2010; 85(5): 657-67.

Das K, Basak S, Ray S. A Study on Superficial Fungal Infection from West Bengal: A Brief Report. J Life Sci. 2009; 1(1): 51-55.

Kamothi MN,Patel BP, Mehta SJ,Kikani KM, Pandya JM. Prevalence of dermatophyte infections in district Rajkot. Electronic Journal of Pharmacology and Therapy. 2010; 3: 1-3.

Grover S, Roy P. Clinico-mycological profile of superficial Mycosis in a hospital in North East India. Medical Journal Armed Forces India. 2003;59 (2): 11416.

Mayr A. Infections which humans in the household transmit to dogs and cats. Zentralbl. Bakteriol. Mikrobiol. Hyg. Ser. 1989; 187: 508-26.

Lakshman A, Ganeshkumar P, MohanSR, Hemamalini M, Madhvan R Epidemiological and clinical pattern of dermatomycoses in rural India. Indian $\mathbf{J}$ Med Microbiol.2015;33:134-6.

Aya S, Jose RFM, Maria EHM, Matilde R, Nancy AG, Celso JG, et al., HLA in Brazilian Ashkenazic Jews with chronic dermatophytosis caused by Trichophyton rubrum. Brazilian $\mathbf{J}$ microbial 2004; 35:69-73. 
Peerapur BV, Inamdar AC,Pushpa PV, Srikant B. Clinicomycological study of dermatophytosis in Bijapur. Indian $\mathbf{J}$ Med Microbiol.2004;22(4): 273-4

Viguie C T, Ancelle N, Savaglio J, Camet D, Schaefer T. Enque^te e'pide'miologique sur les teignes a` Trichophyton soudanense en milieu scolaire. J. Mycol. $1992 ; 2: 160-63$.

\section{How to cite this article:}

Nidhi Negi, Vibha Tripathi, Reshmi Chanda Choudhury, Jitendra Singh Bist, Neeti Kumari and Iva Chandola. 2017. Clinicomycological Profile of Superficial Fungal Infections Caused by Dermatophytes in a Tertiary Care Centre of North India. Int.J.Curr.Microbiol.App.Sci. 6(8): 3220-3227. doi: https://doi.org/10.20546/ijcmas.2017.608.384 